\title{
Genetic variation of xylem hydraulic properties shows that wood density is involved in adaptation to drought in Douglas-fir (Pseudotsuga menziesii (Mirb.))
}

\author{
Guillermina Dalla-Salda • Alejandro Martinez-Meier • \\ Hervé Cochard • Philippe Rozenberg
}

Received: 31 August 2010 /Accepted: 23 January 2011 /Published online: 31 May 2011

(C) INRA and Springer Science+Business Media B.V. 2011

\begin{abstract}
- Introduction Relationships between wood density and hydraulic efficiency and safety (hydraulic specific conductivity and vulnerability to cavitation, respectively) could clarify the physiological process explaining the impact of density on fitness. We have used new, relatively high-throughput phenotyping methods to estimate genetic variation of wood hydraulic specific conductivity $\left(k_{\mathrm{s}}\right)$ and vulnerability to cavitation (VC) as an important step toward demonstrating the adaptive value of wood density.

- Objective The first aim of this study is to test if, in Douglas-fir, there is a relationship between wood hydraulic properties $\left(k_{\mathrm{s}}\right.$ and $\left.\mathrm{VC}\right)$ and wood density. The second
\end{abstract}

Handling Editor: Erwin Dreyer

G. Dalla-Salda $(\bowtie)$

Instituto Nacional de Tecnología Agropecuaria (INTA) Bariloche, Unidad de Ecología Forestal,

C.C. 277 ,

8400 San Carlos de Bariloche, Río Negro, Argentina

e-mail: gdsalda@bariloche.inta.gov.ar

\section{A. Martinez-Meier}

Instituto Nacional de Tecnología Agropecuaria (INTA) Bariloche,

Unidad de Genética Ecológica y Mejoramiento Forestal,

C.C. 277 ,

8400 San Carlos de Bariloche, Río Negro, Argentina

H. Cochard

Institut National de la Recherche Agronomique (INRA)

Clermont-Ferrand, PIAF,

Site de Crouel, Avenue du Brézet,

63100 Clermont-Ferrand, France

\section{P. Rozenberg}

Institut National de la Recherche Agronomique (INRA) Orléans, Unité Amélioration Génétique et Physiologie Forestières,

2163 Avenue de la Pomme de Pin, CS 40001 ARDON,

45075 Orléans Cedex 2, France objective is to estimate genetic variation of wood $k_{\mathrm{s}}$ and VC. These results could aid understanding of the role of wood density in the hydraulic properties of xylem and may clarify the role of wood density in adaptation to drought.

- Results Many significant relationships were found between wood density and wood hydraulic properties at clone and tree level, as well as significant genetic variation for $k_{\mathrm{s}}$ and VC. We have also found positive correlations between tree height, specific conductivity and vulnerability to cavitation, but no relation was found between radial growth and hydraulic variables.

- Conclusions Our results suggest that wood density has an adaptive value and that microdensity can be used to study adaptation to drought in Douglas-fir. The novel methods used to measure $k_{\mathrm{s}}$ and $\mathrm{VC}$ proved to be interesting alternatives for localized measurement of wood hydraulic properties and were compatible with a robust estimation of genetic variation.

Keywords Adaptation to drought . Wood density . Douglas-fir $\cdot$ Hydraulic efficiency $\cdot$ Hydraulic safety

\section{Introduction}

Conduit lumen diameter, conduit length and cell wall thickness are known to radically affect sap conduction efficiency and protection against cavitation and wall collapse (Cruiziat et al. 2002; McElrone et al. 2004; Sperry et al. 2008; Tyree et al. 1994). The lumen to cell wall proportion of the xylem is closely related to wood density (Bucci et al. 2004; Hacke et al. 2001a; Stratton et al. 2000). Several authors (Domec and Gartner 2002a, b; Hacke et al. 2001a, b; Mayr and Cochard 2003; Stiller 2009) showed that wood density is closely related to the hydraulic 
properties of the xylem. A recent study has shown that Douglas-fir trees surviving the 2003 heat and drought wave in France had a significantly higher wood density than trees that died shortly after the heat wave (Martinez-Meier et al. 2008). Dalla-Salda et al. (2009) found that a Douglas-fir clone more resistant to cavitation had a higher wood density than other, more vulnerable, clones. All these results suggest that wood density may be an adaptive trait involved in resistance to drought.

Phenotypic variation of wood hydraulic properties involved in resistance to drought can affect surviving capacity within a tree population and thus fitness. If the wood hydraulic properties involved in resistance to drought are genetically variable and heritable, then favourable phenotypes can be selected and transmitted to the next generation. While it is well known that between-species variation exists for wood hydraulic properties (Bond and Kavanagh 1999; Cavender-Bares and Holbrook 2001; Domec et al. 2007; Sperry and Tyree 1990) and that there is genetic variation for wood density (Cornelius 1994; Johnson and Gartner 2006), fewer results are available concerning within-species genetic variation of wood hydraulic properties related to hydraulic efficiency and safety (Dalla-Salda et al. 2009; Rosner et al. 2007, 2008; Vander Willigen and Pammenter 1998).

Nowadays, relatively high-throughput phenotyping methods for wood hydraulic properties allow rapid, localized measurement of specific conductivity $\left(k_{\mathrm{s}}\right)$ (DallaSalda et al. 2009) and resistance to cavitation in the wood of adult trees (Cochard 2002; Cochard et al. 2005). This is in accordance with the number of trees compatible with a robust estimation of genetic variation. The indirect X-ray microdensity method developed by Polge (1966) is largely used in genetic improvement programs for the selection of trees with desirable density characteristics. These profiles allow the description of wood density variation within a tree ring, through the radius, with a precision of several micrometres. Combining these methods, we can measure $k_{\mathrm{s}}$, vulnerability to cavitation (VC) and wood density in exactly the same portion of wood.

The first aim of this study is to test whether, in Douglasfir, there is a relationship between wood hydraulic properties $\left(k_{\mathrm{s}}\right.$ and $\left.\mathrm{VC}\right)$ and wood density. The second objective is to estimate genetic variation of wood $k_{\mathrm{s}}$ and VC. If there is genetic variation of $k_{\mathrm{s}}$ and VC, then it could be possible to select genotypes with desirable hydraulic characteristics within the framework of a Douglas-fir breeding program. If we find that there is a relationship between hydraulic properties ( $k_{\mathrm{s}}$ and $\mathrm{VC}$ ) and certain wood density traits, they could be used to indirectly select genotypes with advantageous hydraulic properties. In all cases, these results could help in the understanding of the role of wood density in the hydraulic properties of xylem, thus clarifying the role of wood density in adaptation to drought.

\section{Materials and methods}

Douglas-fir trees used for this study belong to a clonal experimental trial installed in Orléans, France, by INRA. The 18-year-old trees belong to seven clones chosen from a total of 27 clones planted at the same site. Randomly selected clones had at least three healthy trees, not more than $4 \mathrm{~m}$ apart, in order to minimize within-clone environmental variation. In each tree, we measured total height (height) and stem circumference at breast height (circ).

For each clone, three trees were felled during March 2008. Pieces of stem of $30 \mathrm{~cm}$ were cut at $0.10,1.30$ and $3 \mathrm{~m}$ from the base (hereafter "positions"). From each tree, we also cut a $60-\mathrm{cm}$ piece next to the base of the stem (Fig. 1). All samples were soaked in plastic tanks filled with water in order to prevent water loss. Samples were sawn to: three discs per tree of $15 \mathrm{~cm}$ thickness and a piece of stem (initially $60 \mathrm{~cm}$ between 0.10 and $1.30 \mathrm{~m}$ ) of $40 \mathrm{~cm}$. All discs were used to measure specific hydraulic conductivity $\left(k_{\mathrm{s}}\right)$ and microdensity variables. $k_{\mathrm{s}}$ was measured in earlywood of tree rings 2005, 2006 and 2007, and in the same tree rings, microdensity profiles were obtained using the X-ray indirect method developed by Polge (1966) (Fig. 1). The 40-cm piece of stem was kept to make the vulnerability curves. Samples were kept wet during the cutting process and were immediately placed in large plastic containers filled with fresh water. All plant material was maintained in wet condition and in a cold chamber at $2{ }^{\circ} \mathrm{C}$ to prevent cavitation.

\section{$2.1 k_{\mathrm{s}}$ measurements}

Immediately before doing the $k_{\mathrm{s}}$ measurements, the $15-\mathrm{cm}$ discs were sawn under water jet in a humid atmosphere in order to obtain a 5 -cm-thick disc that was kept in water.

To measure localized axial hydraulic conductivity in tree rings $\left(k_{\mathrm{s}}\right.$ ) (Dalla-Salda et al. 2009), we used 2-mm-diameter veterinary needles, connected individually to the end of a water column using flexible plastic tubes. Three needles were carefully inserted with a rubber hammer into the earlywood of each ring, under water. The operation was repeated for three successive sapwood rings $(2005,2006$ and 2007) in the three discs cut at three heights in each tree. $k_{\mathrm{S}}$ was thus measured 27 times per tree $(3$ needles $\times 3$ rings $\times$ 3 discs ). To prevent air bubbles, the needles were filled with water using a thinner needle and a syringe.

After inserting and filling the nine needles of a disc, we took the disc out of the water and connected only one of the 
Fig. 1 Scheme showing the cutting method and sample's destination. Three discs were taken from each tree (at 0.10 , 1.30 and $3 \mathrm{~m}$ ). In each disc, we measured specific hydraulic conductivity $\left(k_{\mathrm{s}}\right)$ locally matching microdensity measurements. $k_{\mathrm{s}}$ measurements were conducted in 2005, 2006 and 2007 tree rings. Vulnerability curves were constructed using 2007 tree ring from a piece of stem taken between the $0.10-\mathrm{m}$ and the $1.30-\mathrm{m}$ discs

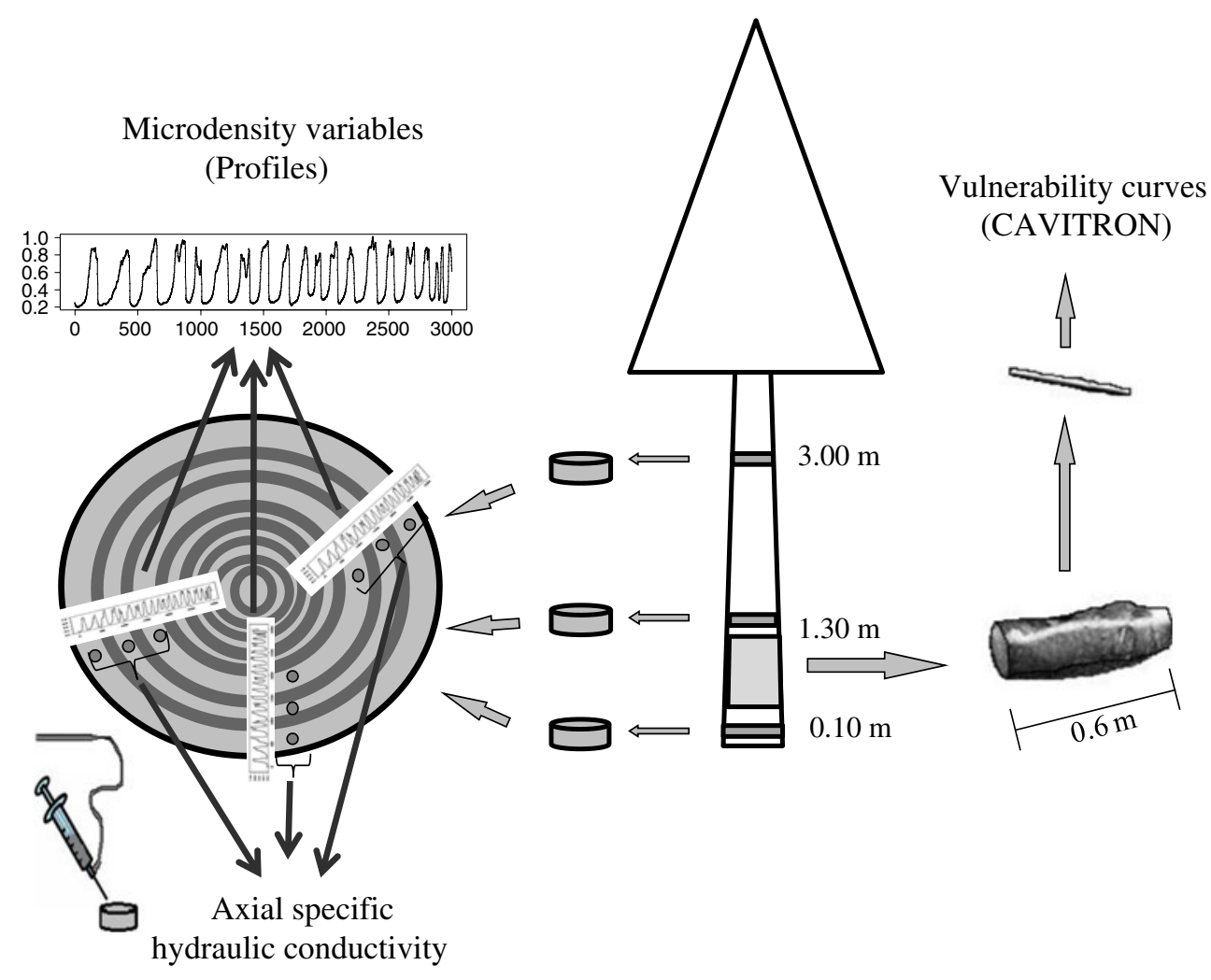

needles to the water column through a stopcock and laboratory tubing. The other extremity of the $120-\mathrm{mm}-$ long column was connected to a micro-pipette (placed horizontally) allowing reading of the variation in water volume with time.

The system was filled with distilled Phloxine coloured water, making reading easier and permitting permanent verification of dripping and absence of air bubbles. In addition, we could verify that coloured water really passed through the sample and arrived exactly at the other side, in the same portion of the ring where the needle was inserted. In all the cases, needles were installed avoiding compression of the wood. We assume that the samples were near water saturation, thus presenting a $k_{\mathrm{s}}$ near maximum conductivity at the moment of measurement. This assumption was not only because all precautions were taken during sample manipulation but also because the trees were cut at the very beginning of a humid, cool, rainy 2008 spring following the 2007 growing season in Orléans, France, which was also especially humid and cool.

Sapwood's specific conductivity $\left(\mathrm{k}_{\mathrm{s}}\right)$ was calculated according to Darcy's law:

$k_{s}=\frac{V \times L \times \eta}{t \times A \times \Delta P}$

where $V$ is the volume of water that went through the sample (cubic metres), $L$ is the sample length (metres), $\eta$ is the viscosity of water at the temperature at which the experiments were conducted (newton second per square metre), $t$ is the time (seconds), $A$ the cross-sectional area (square metre) of the sample (in this case it corresponds to the needle's internal area) and $\Delta P$ is the pressure difference (pascals) between ends of the sample. $k_{\mathrm{s}}$ was expressed in square metre as a consequence of separating the viscosity $(\eta)$ from the driving agent in terms of a pressure difference. Thus, $k_{\mathrm{s}}$ is determined only by wood structure and is independent of the nature of the fluid (Domec and Gartner 2002b).

\subsection{Vulnerability to cavitation curves (VC)}

In order to obtain the pieces of wood compatible with the measuring equipment, we extracted four to six longitudinal portions from each trunk, splitting the trunk with an axe and a hammer, following the wood grain (Fig. 1). The 2007 tree ring was large enough to comprise the entire VC sample that is a $0.7 \times 0.7 \times 26.5$-cm vertical stick. Samples were always manipulated in humid conditions using a shallow pan filled with water and kept in a cold chamber $\left(2-3^{\circ} \mathrm{C}\right)$ when not in use. Three samples were cut and measured per tree.

To establish the vulnerability curves, we used a CAVITRON (Cochard 2002; Cochard et al. 2005). This technique uses centrifugal force to lower xylem pressure in the sample and to induce a positive pressure gradient 
between sample ends and thus a flow of water through the sample. By measuring this flow, it is then possible to determine how the sample hydraulic conductance varies as the centrifugal force is increased (Cochard et al. 2005).

In our case, samples were not saturated to restore maximum conductivity in order to avoid cavitation fatigue. Refilling may also leave behind small micro-bubbles that could nucleate cavitation during subsequent stress (Hacke et al. 2001b).

Once the vulnerability curves were constructed, a nonlinear sigmoidal Boltzmann function was fitted to compute the percentage loss of conductivity (PLC) at tree level. Four parameters were calculated to describe PLC variation: the P12, P50 and P88 (value of the $x$ pressure-axis of the curve with $12 \%, 50 \%$ and $88 \%$ loss of conductivity) and the maximum slope of the VC curve (located at the inflexion point), calculated according to Domec and Gartner (2001).

The P12 value is termed the air entry point (Sparks and Black 1999) and is an estimate of the xylem tension at which pit membranes are overcome within the conducting xylem when cavitation starts. P50 is the point of $50 \%$ loss of hydraulic conductivity. Likewise, P88 represents the full embolism point and is interpreted as an approximation of the actual maximum tension of the xylem before failing and becoming non-conductive (Domec and Gartner 2001). As suggested by Sperry (1995), the slope can be considered as a measure of the xylem safety margin between P12 and P88.

\subsection{Microdensity variables}

The discs from $0.10,1.30$ and $3 \mathrm{~m}$, after being used to measure $k_{\mathrm{s}}$, were sawn with a double-blade saw in order to obtain wood stripes precisely located next to the $k_{\mathrm{s}}$ measurements. These were about $8 \mathrm{~mm}$ wide and $1.5 \mathrm{~mm}$ thick and as long as the sample radius.

They were then oven-dried up to moisture equilibrium at $60^{\circ} \mathrm{C}$ and subsequently analysed by indirect X-ray microdensitometry (Polge 1966). The resulting X-ray films were scanned at 1,000 dpi resolution with 8 bits per pixel. The digitalized images were processed using WinDENDRO, Regent Instruments Inc. (Guay et al. 1992), obtaining a microdensity profile with a spatial resolution of $25 \mu \mathrm{m}$. The last step of the data process used a computer routine written in R language ( $\mathrm{R}$ Development Core Team 2009) to assess the following ring variables: ring width (RW), mean ring density (MRD), minimum ring density (MID), maximum ring density (MAD), earlywood density (EWD), latewood density (LWD), earlywood proportion (EWP) and the mean density of the first 100 within-ring microdensity values (SEQ, i.e. the mean density of the first 2.5 -mm-wide part of the earlywood). This last parameter was calculated from the point where the veterinary needle used to measure $k_{\mathrm{s}}$ was inserted into the first $2.5 \mathrm{~mm}$ of the earlywood (Fig. 2).

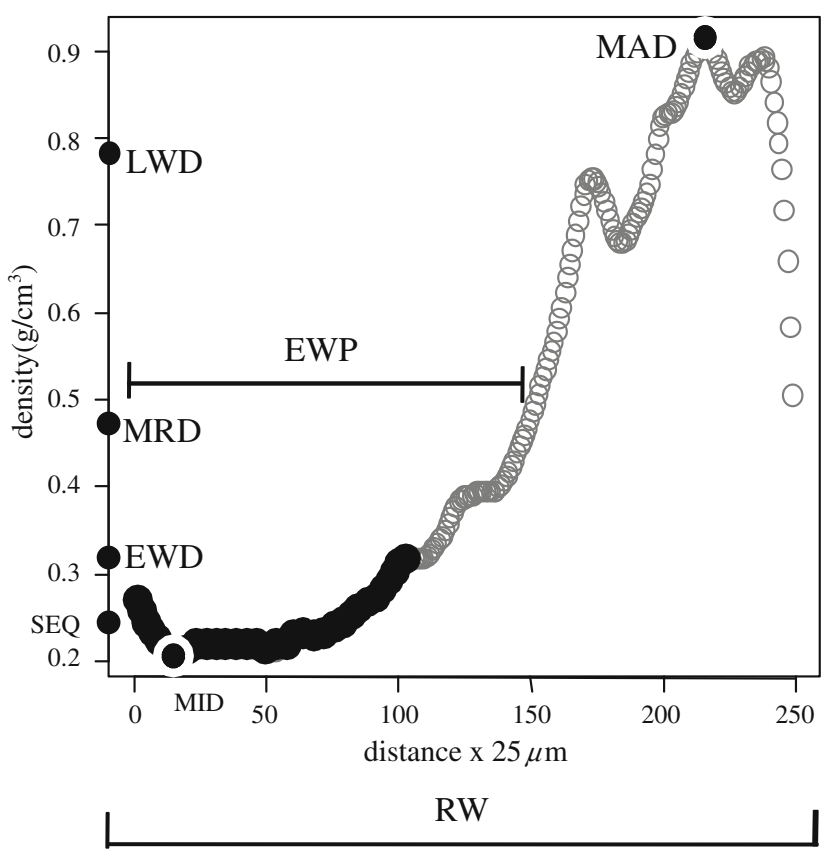

Fig. 2 Tree ring's density values calculated from a microdensity profile of one typical Douglas-fir tree ring, showing ring width $(R W)$, mean ring density $(M R D)$, minimum ring density $(M I D)$, earlywood density $(E W D)$, earlywood proportion $(E W P)$, mean density of the first 100 within-ring microdensity values $(S E Q)$ corresponding to the dark portion points, maximum ring density $(M A D)$ and latewood density $(L W D)$

\subsection{Statistical analysis}

\subsubsection{Relationship between hydraulic properties and microdensity variables and growth traits (circumference and height)}

Circumference (circ) and tree height (height) were measured in all trees before tree felling. For each $k_{\mathrm{s}}$ value, we have a microdensity value measured exactly next to it. All the $k_{\mathrm{s}}$ measurements were used to study the association between $k_{\mathrm{s}}$ and microdensity variables. To study the association between $\mathrm{VC}$ and microdensity variables, we used the microdensity variables computed in the 2007 tree ring sampled at breast height. In order to assess the relationships between growth traits and hydraulic variables, each hydraulic variable was averaged at tree level. Associations were computed at tree and clone levels. We used Pearson correlation coefficients that were computed using R software (R Development Core Team 2009).

\subsubsection{Phenotypic and genetic variation of wood hydraulic properties: $k_{s}, P 12$, P50, P88 and slope}

The following model was used to assess the significance of the $k_{\mathrm{s}}$ variation in positions $(0.10,1.30$ and $3 \mathrm{~m}$ ), years (tree rings) and clones. Logarithm of $k_{\mathrm{s}}$ was used for normality 
assumption:

$y_{i j h}=\mu+\alpha_{i}+\beta_{j}+\chi_{h}+(\alpha \beta)_{i j}+(\alpha \chi)_{i h}+(\beta \chi)_{j h}+\varepsilon_{i j h}$

where $y_{i j h}$ is the $i j h$ th logarithm of $k_{\mathrm{s}}$ observed variable; $\mu$ is the overall mean; $\alpha_{i}$ is the fixed effect of the $i$ th position $(0.10,1.30$ and $3 \mathrm{~m}) ; \beta_{j}$ is the fixed effect of the $j$ th tree ring, $\chi_{h}$ is the fixed effect of the $h$ th clone; $(\alpha \beta)_{i j},(\alpha \chi)_{i h}$ and $(\beta \chi)_{j h}$ are the corresponding interaction effects between position and tree ring, between position and clones and between tree ring and clone, respectively; and $\varepsilon_{i j h}$ is the random error.

Note that for PLC variables and slope, measurements were taken only in the 2007 tree ring in a 40-cm-long sample taken below the breast height region. Thus, position and tree ring effects are not present as sources of variation. The following model was used to assess significant differences between clones for the parameters of the vulnerability curves (P12, P50, P88 and slope):

$y_{i j}=\mu+\tau_{i}+\varepsilon_{i j}$

where $y_{i j}=i j$ th PLC observed variable, $\mu=$ overall mean, $\tau_{i}=$ fixed effect of the $i$ th clone and $\varepsilon_{i j}=$ random error.

\subsubsection{Phenotypic and genetic variation of microdensity variables: $R W, M R D, M I D, E W D, E W P, S E Q, M A D$ and $L W D$}

To quantify phenotypic variation in microdensity parameters, we separated the different sources of variation: position, tree ring and genetics. Through $\mathrm{R}$ ( $\mathrm{R}$ Development Core Team 2009), we estimated tree ring (2005, 2006 and 2007), position and clone effects for all microdensity variables.

To assess the significance of the variation in the microdensity variables, the following model was used:

$y_{i j h}=\mu+\alpha_{i}+\beta_{j}+\chi_{h}+(\alpha \beta)_{i j}+(\alpha \chi)_{i h}+(\beta \chi)_{j h}+\varepsilon_{i j h}$

where $y_{i j h}$ is the $i j h$ th observed microdensity variable; $\mu$ is the overall mean; $\alpha_{i}$ is the fixed effect of the $i$ th position; $\beta_{j}$ is the fixed effect of the $j$ th tree ring; $\chi_{h}$ is the fixed effect of the $h$ th clone; $(\alpha \beta)_{i j},(\alpha \chi)_{i h}$ and $(\beta \chi)_{j h}$ are the corresponding interaction effects between position and tree ring, between position and clones and between tree ring and clone, respectively; and $\varepsilon_{i j h}$ is the random error.

\section{Results}

\subsection{General results on the study characters}

Table 1 shows general mean, coefficient of variation, and minimum and maximum values for growth traits, wood hydraulic properties and microdensity variables.
Table 1 Mean, phenotypic coefficient of variation $\left(\mathrm{CV}_{\mathrm{p}}\right)$, and minimum $(\min )$ and maximum $(\max )$ of analysed variables

\begin{tabular}{lcccc}
\hline & Mean & $\mathrm{CV}_{\mathrm{p}}(\%)$ & Min & Max \\
\hline Growth traits & & & & \\
Circ $(\mathrm{cm})$ & 34.2 & 13.2 & 24 & \multicolumn{1}{c}{42} \\
Height $(\mathrm{m})$ & 6.3 & 7.8 & 5.8 & 7.3 \\
Hydraulic variables & & & & \\
$k_{\mathrm{s}}\left(\mathrm{m}^{2}\right)$ & $4.56^{-12}$ & 35.36 & $1.56^{-12}$ & 1.03 \\
P12 $(\mathrm{MPa})$ & -1.36 & 27.28 & -1.80 & -0.89 \\
P50 $(\mathrm{MPa})$ & -2.48 & 30.32 & -3.11 & -1.91 \\
P88 $(\mathrm{MPa})$ & -3.22 & 30.17 & -3.93 & -2.76 \\
Slope & 72.70 & 32.30 & 45.85 & 132.30 \\
Microdensity variables & & & \\
RW $(\mathrm{mm})$ & 8.41 & 28.80 & 1.34 & 16.51 \\
MRD $\left(\mathrm{g} / \mathrm{cm}^{3}\right)$ & 0.43 & 14.19 & 0.30 & 0.69 \\
MID $\left(\mathrm{g} / \mathrm{cm}^{3}\right)$ & 0.22 & 21.09 & 0.15 & 0.49 \\
EWD $\left(\mathrm{g} / \mathrm{cm}^{3}\right)$ & 0.32 & 17.38 & 0.19 & 0.68 \\
EWP $(\%)$ & 73.31 & 17.04 & 34.72 & 94.06 \\
SEQ $\left(\mathrm{g} / \mathrm{cm}^{3}\right)$ & 0.26 & 24.31 & 0.17 & 0.69 \\
MAD $\left(\mathrm{g} / \mathrm{cm}^{3}\right)$ & 0.84 & 8.02 & 0.47 & 0.97 \\
LWD $\left(\mathrm{g} / \mathrm{cm}^{3}\right)$ & 0.70 & 9.97 & 0.36 & 0.85 \\
\hline
\end{tabular}

The date of measurement does not have any significant effect on $k_{\mathrm{s}}$ nor on VC (data not shown), indicating that harvesting, storage and measurement methods can be accepted.

Measured at three different positions $(0.10,1.30$ and $3 \mathrm{~m}), k_{\mathrm{s}}$ was found to decrease significantly $(p<0.05)$ from the base of the stem to the crown. All microdensity variables related to the first part of the tree ring, SEQ, MID, EWD and EWP, increased significantly in this direction $\left(p<2.2^{-16}\right)$, while LWD and MAD decreased significantly $\left(p<2.2^{-16}\right)$.

3.2 Relationships between wood hydraulic properties, microdensity variables and growth traits

In Table 2, we show the significant phenotypic correlations and their associated probability at tree and clonal levels between microdensity variables, growth traits and wood hydraulic properties.

Non-significant correlations were found between RW and wood hydraulic properties, while many significant correlations were found between wood hydraulic properties and microdensity variables. Strong positive correlations were found between $k_{\mathrm{s}}$ and EWP at the clonal level. Moderate positive correlations were found between $k_{\mathrm{S}}$ and EWP, MAD and LWD at the individual level, and between slope and MAD at the clonal level. Strong negative correlations were found between $k_{\mathrm{s}}$ and MID, $k_{\mathrm{s}}$ and SEQ 


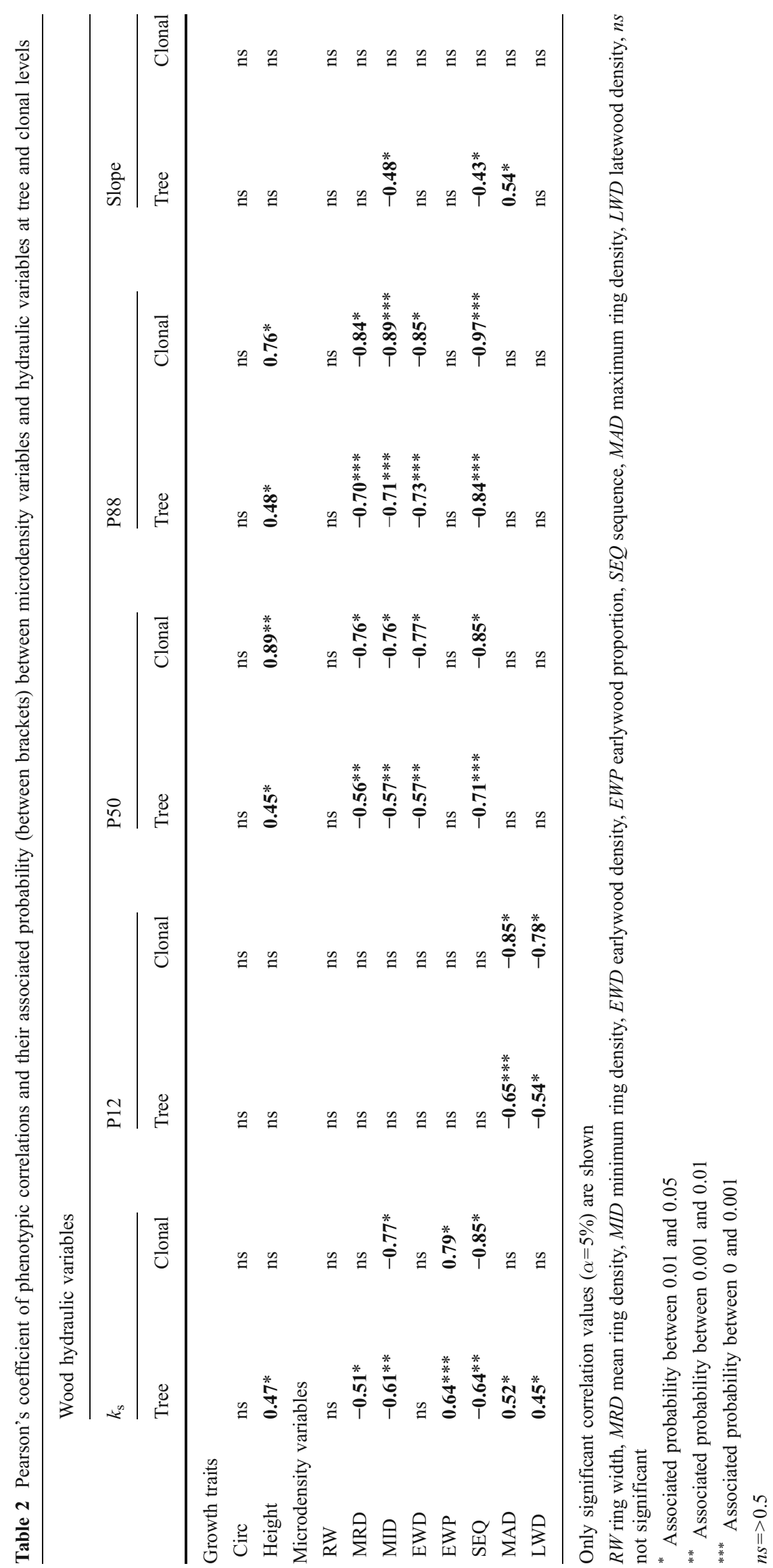


(Fig. 3), P12 and MAD (Fig. 3), P12 and LWD, P50 and MID, EWD, SEQ (Fig. 3) and finally P88 and MID, EWD and SEQ (Fig. 3) at the clonal level. Strong negative correlations at the tree level were found between P50 and SEQ and between P88 and MID, EWD, SEQ. Moderate negative correlations at the tree level were found between $k_{\mathrm{S}}$ and MID and $k_{\mathrm{S}}$ and SEQ, P12 and MAD, P12 and LWD, P50 and MID and P50 and EWD, slope and MID and slope and SEQ. MRD is moderately and negatively related to $k_{\mathrm{S}}$ and to P50 at the tree level and is strongly and negatively correlated to P50 at the clonal level and to P88 at both tree and clonal level.

No correlation was found between circ and wood hydraulic properties. At the individual level, moderate positive correlations were found between height and $k_{\mathrm{s}}$, P50 and P88. At the clone level, we also found strong positive correlations between tree height and P50 and P88.

3.3 Genetic variation of growth traits, wood density and wood hydraulic properties

\subsubsection{Growth traits}

Our results show that clones are significantly different for circumference and height (Fig. 4).

\subsubsection{Microdensity variables}

A significant clonal effect was found for all microdensity variables (Table 3). Position and tree ring effects were also significant for all variables except for MRD and MAD, respectively.

In Fig. 5, we show MRD, MID, SEQ and MAD variation with respect to clone and position.

\subsubsection{Hydraulic properties}

A significant effect of clone, position and of their interaction was found for the logarithm of $k_{\mathrm{s}}$, whereas the effect of tree ring was not found significant (Table 4).

The VC curves at clone level are shown in Fig. 6. A significant genetic effect was found for slope, P12, P50 and P88 (see Table 5).

\section{Discussion}

Our results concerning $k_{\mathrm{s}}$ and $\mathrm{VC}$ are consistent with those of our previous study with three different clones (DallaSalda et al. 2009) and those found in Douglas-fir and other species by several authors for similar, younger and older trees (Domec and Gartner 2001, 2002a, b; Mayr and Cochard 2003; Sperry and Ikeda 1997). This demonstrates the effectiveness of the methods developed, tested and used to measure these variables. These results could not only help to facilitate studies on hydraulic properties (accurate, localized and faster measurements) but could also favour to the development of selection criteria based on microdensity profiles, attainable with wooden cores. In the present context of global climatic change, associating genetic and ecophysiological studies is of particular importance.
Fig. 3 Many significant correlations were found between wood hydraulic properties and microdensity variables. For example, strong negative correlations were found at clone level between: $\mathbf{A} k_{\mathrm{s}}$ and SEQ $(-0.85)$, B P50 and SEQ (-0.85), C P88 and SEQ $(-0.97)$ and D P12 and MAD $(-0.85)$
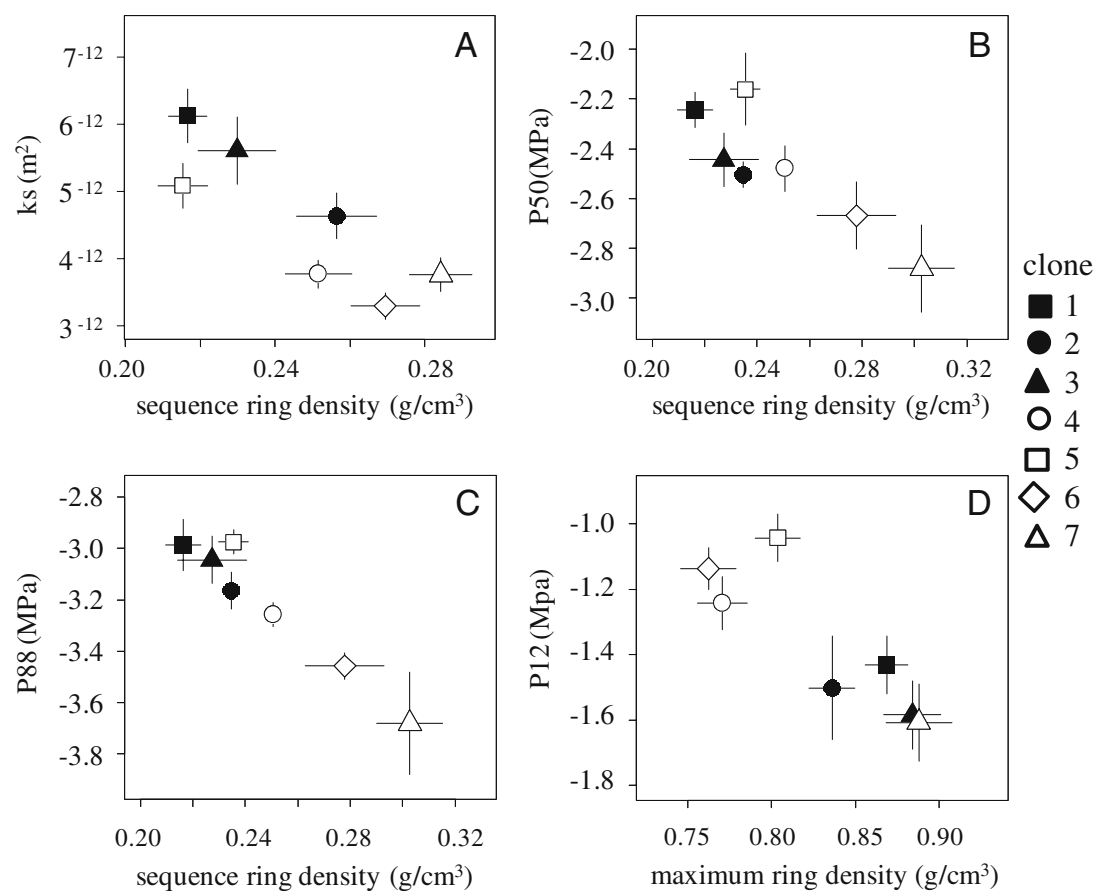
Fig. 4 Circumference and height boxplot (clone's mean and standard deviation). Clones are significantly different for circumference and height. Similar letters show no significant differences, Tukey's test $(\alpha=5 \%)$
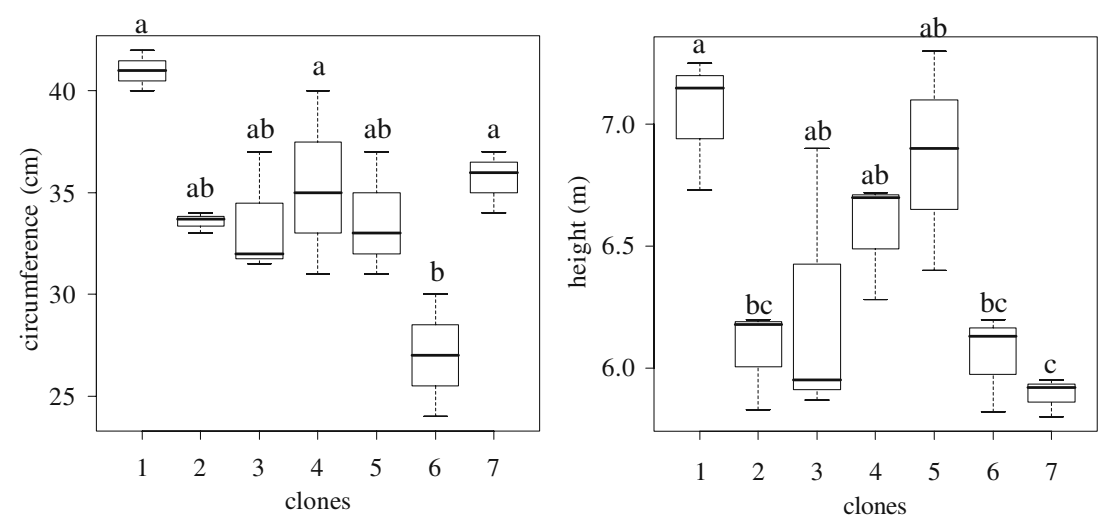

In contrast to tree circumference, tree height is related to tree hydraulics. Fast height-growing Douglas-fir trees are probably not only more conductive but also more vulnerable to cavitation. We have to take into account that sampling was realised at fixed heights (at 0.10, 1.30 and $3 \mathrm{~m}$ ) and therefore wood of different cambial ages is being compared. Nevertheless, this difference is never greater than 2 or 3 years. We assume that environmental variation is not relevant since the experimental plot the trees were taken from is a homogeneous terrain in the INRA nursery and the studied clones are separated by less than $30 \mathrm{~m}$.

No correlation was found between ring width (RW) and wood hydraulic properties. Plots of ring width against PLC variables at clone level (not shown here) reveal that at least for the plant material sampled in this study, it may be possible to find fast growing clones with high resistance to drought. Except for RW, each microdensity variable is significantly correlated to at least one hydraulic property. $k_{\mathrm{s}}$ is mostly negatively related to earlywood density variables (MID and SEQ), but not to EWD. This is probably due to the fact that EWD is mean density of a ring segment including not only earlywood but also a large part of transition wood from earlywood to latewood. In contrast, MID and SEQ are completely enclosed in earlywood.

P12 is mostly negatively correlated to latewood density variables (MAD and LWD). The strongest correlation is found for MAD, which is thus the best candidate for indirectly estimating P12. This is consistent with the results found by Domec and Gartner (2002b). Checking and, if confirmed, trying to understand this relationship will be a subject developed in another study. Here, we emphasize that this correlation can be considered as a method to indirectly estimate P12, at least in similar plant material. P50 and P88 are both principally negatively correlated to earlywood density variables. The strongest correlation is with SEQ, which is here again a good candidate for the indirect estimation of P50 and P88. Higher density values in the first part of the Douglas-fir tree ring imply higher resistance to drought in detriment to $k_{\mathrm{s}}$.

We demonstrate that in Douglas-fir, there is a relationship between wood density and wood hydraulic properties. Therefore, wood density is related to Douglas-fir hydraulic functioning: this is a first outcome tending to reveal wood density as a quantitative trait marker of adaptation in Douglas-fir.

Relationships between density and resistance to cavitation were not observed in other studies (Domec and Gartner 2002a; Dutilleul et al. 1998; Rosner et al. 2007). This may be related to the fact that not only conduit internal dimension but also cell wall pitting plays an important role in resistance to cavitation through embolism initiation and propagation (Pittermann et al. 2006). However, in all of
Table $3 F$ value and probability (Pr) associated to the ANOVA fixed effects for the microdensity variables

$n s$ not significant

\begin{tabular}{|c|c|c|c|c|c|c|}
\hline \multirow[t]{2}{*}{ Variable } & \multicolumn{2}{|l|}{ Clone } & \multicolumn{2}{|l|}{ Position } & \multicolumn{2}{|c|}{ Tree ring } \\
\hline & $F$ value & $\operatorname{Pr}(>F)$ & $F$ value & $\operatorname{Pr}(>F)$ & $F$ value & $\operatorname{Pr}(>F)$ \\
\hline RW & 25.92 & $<2.2^{-16}$ & 8.03 & 0.004 & 144.75 & $<2.2^{-16}$ \\
\hline MRD & 69.04 & $<2.2^{-16}$ & 1.80 & ns & 14.05 & $1.7^{-06}$ \\
\hline MID & 29.27 & $<2.2^{-16}$ & 63.31 & $<2.2^{-16}$ & 6.43 & 0.002 \\
\hline EWD & 46.33 & $<2.2^{-16}$ & 35.88 & $2.6^{-14}$ & 56.83 & $<2.2^{-16}$ \\
\hline EWP & 27.29 & $<2.2^{-16}$ & 6.01 & 0.003 & 55.10 & $<2.2^{-16}$ \\
\hline SEQ & 32.46 & $<2.2^{-16}$ & 93.49 & $<2.2^{-16}$ & 12.35 & $8.0^{-06}$ \\
\hline MAD & 23.85 & $<2.2^{-16}$ & 54.94 & $<2.2^{-16}$ & 0.18 & ns \\
\hline LWD & 25.28 & $<2.2^{-16}$ & 68.11 & $<2.2^{-16}$ & 9.40 & 0.001 \\
\hline
\end{tabular}


Fig. 5 Mean ring density (A), minimum ring density $(\mathbf{B})$, sequence ring density $(\mathbf{C})$ and maximum ring density (D) at the three positions $(0.10,1.30$ and $3 \mathrm{~m}$ high) for the seven clones. Each data are a mean of the 2005, 2006 and 2007 tree rings
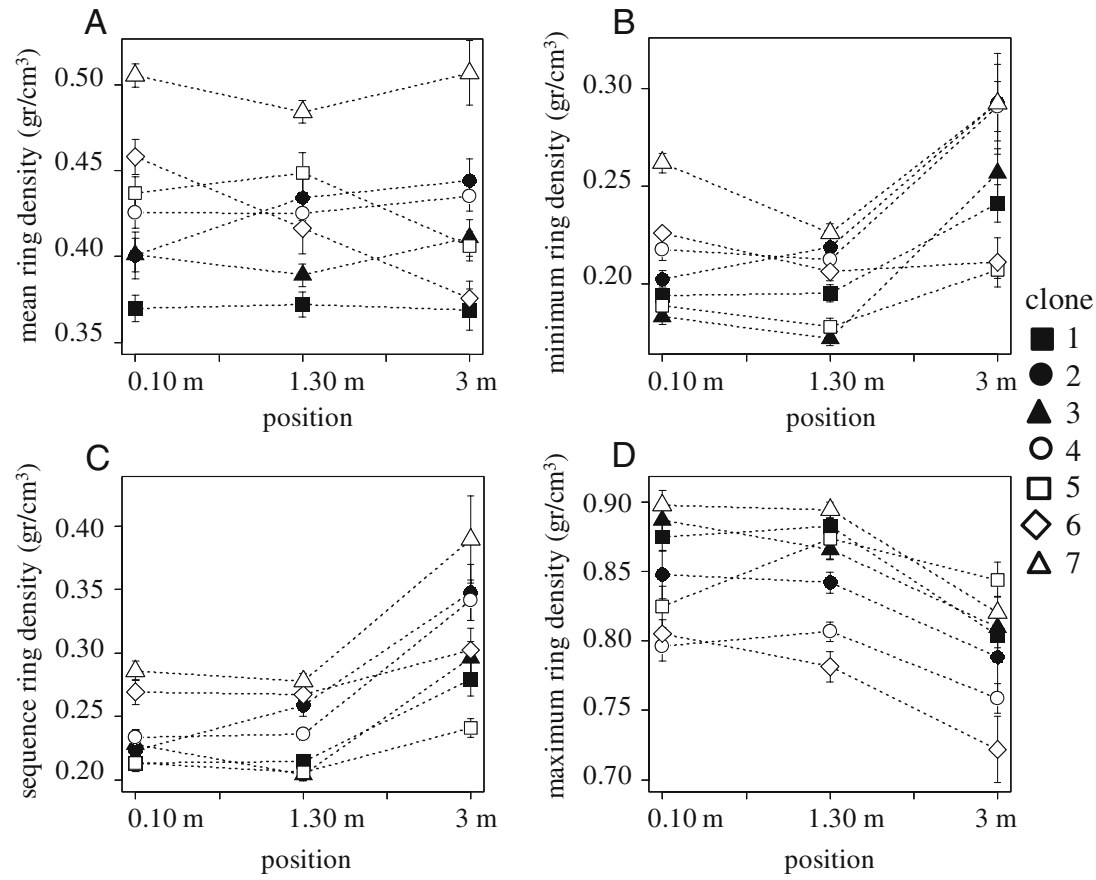

these cases, wood density was measured using gravimetric methods on solid wood samples. In this study, we used the indirect X-ray microdensity method (Polge 1966), which is more precise than the former and which takes into account spatial distribution of the wood material (Decoux et al. 2004), and we were able to differentiate and separate the segments of the microdensity profiles matching the wood volumes used for measuring hydraulic properties inside the rings. Therefore, we increased the precision of the relationship between density and hydraulic properties. In Douglas-fir, there is a strong relationship between withintree ring density increase and both cell wall thickness increase and tracheid diameter diminution in radial and tangential directions (Rathgeber et al. 2006). Thus, through this study, we can conclude that $k_{\mathrm{s}}$ is mainly correlated to earlywood tracheid internal dimensions. This is consistent with already published results (Cruiziat et al. 2002; McElrone et al. 2004; Stiller 2009; Tyree et al. 1994). Therefore, in Douglas-fir, for indirect measurement of $k_{\mathrm{s}}$, the best putative microdensity variable would be SEQ.

Table $4 F$ value and probability (Pr) associated to the ANOVA fixed effects for the logarithm of $k_{\mathrm{s}}$

\begin{tabular}{lrc}
\hline Source of variation & $F$ value & $\operatorname{Pr}(>F)$ \\
\hline Clone & 19.61 & $<2.2^{-16}$ \\
Tree ring & 1.82 & 0.162 \\
Position & 14.45 & $8.04^{-7}$ \\
Tree ring $\times$ position & 2.05 & 0.113 \\
Tree ring $\times$ clone & 0.84 & 0.602 \\
Clone $\times$ position & 2.91 & 0.006 \\
\hline
\end{tabular}

In a preliminary study, Dalla-Salda et al. (2009) measured $k_{\mathrm{s}}$ and VC of another three Douglas-fir clones. These variables were measured in wood that was embolized as a consequence of the 2003 heat wave and drought in France. In this new study, we collected wood samples at the beginning of the 2008 growing season, reducing the possibility of studying wood samples with embolized tracheids. It is interesting to emphasize that this previous study could partially demonstrate the role of wood density in maintaining part of the Douglas-fir xylem functional during the 2003 heat wave and drought in France: the clone

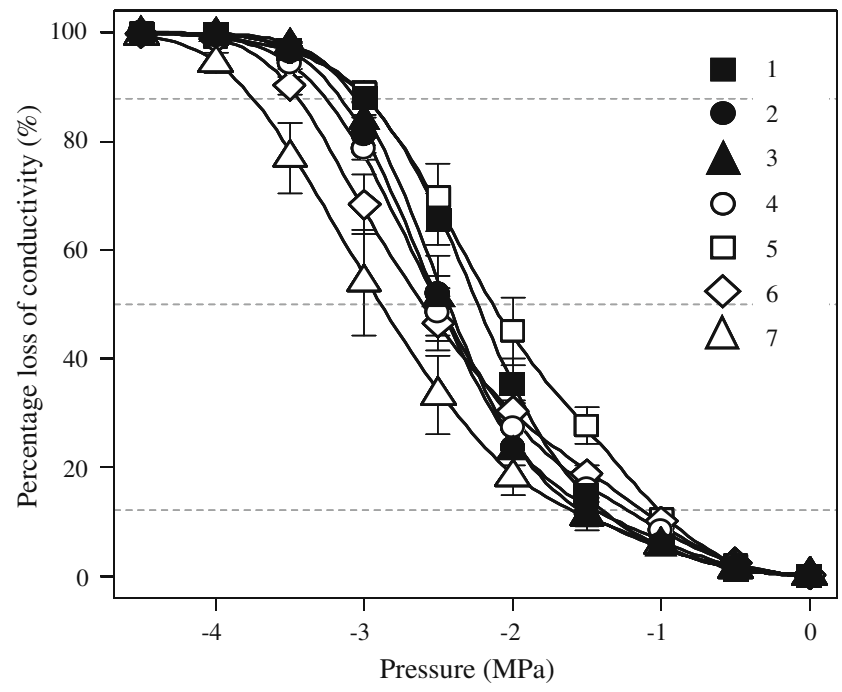

Fig. 6 Mean vulnerability to cavitation (VC) curves at clone level: percentage loss of conductivity (means and standard deviation) as a function of the xylem pressure for the seven Douglas-fir clones 
Table $5 F$ value and probability (Pr) associated to the ANOVA genetic fixed effects for the parameters of the vulnerability curves measured in three different samples per tree (nine curves per clone) for the 2007 tree ring

\begin{tabular}{lcc}
\hline Variable & $F$ value & $\operatorname{Pr}(>F)$ \\
\hline P12 & 3.61 & 0.022 \\
P50 & 3.19 & 0.034 \\
P88 & 5.22 & 0.005 \\
slope & 7.20 & 0.001 \\
\hline
\end{tabular}

most resistant to cavitation (according to P50 measurements) was the clone with the highest MRD and MID. This is consistent with the significant negative correlation we found between MRD, MID and P50 in this study.

Our results also demonstrate that there is significant genetic variation for $k_{\mathrm{s}}$ and VC curve variables in Douglasfir stem wood. These results are consistent with those found in three Douglas-fir clones in the previous study (DallaSalda et al. 2009). Rosner et al. (2007, 2008) also found significant differences between clones for specific hydraulic conductivity in Norway spruce. Other authors (Neufeld et al. 1992; Vander Willigen and Pammenter 1998) showed that there is a significant genetic variation for VC curve variables measured in leaves, branches and seedlings. In our work, the significant genetic variation for VC curve variables was measured directly in the same wood sample where $k_{\mathrm{s}}$ and density were also measured. Our results also show a strong significant clone variation for all microdensity variables. These results highlight the significance of wood density as a quantitative trait marker of Douglas-fir adaptation in the context of global climate change. These findings are a second step toward complete demonstration of the adaptive potential of wood density. More extensive direct or indirect measurements of wood hydraulic properties are necessary to explore the genetic variation of these properties on a larger scale. The strong correlations found between hydraulic and microdensity variables make microdensity profiles promissory not only for the selection of trees with desirable wood density in the framework of breeding programs but also for the indirect study of genetic variation of hydraulic properties and the selection of individuals by these traits.

Measuring $k_{\mathrm{s}}$ in the same tree rings at three different heights (at $0.10,1.30$ and $3 \mathrm{~m}$ ) enabled us to take the cambial age effect into account. From the base of the stem to the crown, $k_{\mathrm{s}}$ variable decreases while earlywood density variables (especially SEQ) increase: this is further indirect evidence of the well-known relationship between conduit internal dimensions and $k_{\mathrm{s}}$. Density increase and the $k_{\mathrm{S}}$ decrease with height is considered a cambial age effect (Zobel and Sprague 1998; Spicer and Gartner 2001). The physical relationship between tracheids internal dimensions and $k_{\mathrm{s}}$ is confirmed at tree level and at clone level by the strong positive correlation found between $k_{\mathrm{s}}$ and earlywood density variables.
In this study, we found that there are significant relationships between wood microdensity variables and wood hydraulic properties, as well as significant genetic variation for $k_{s}$ and VC. This indicates that wood density may have an adaptive value and that it could be used to study adaptation to drought in Douglas-fir. Indirect screening for genetic differences in wood hydraulic properties is possible using the relationship between wood density and xylem hydraulic efficiency and resistance. Through this study, the novel methods used to measure $k_{\mathrm{s}}$ and vulnerability to cavitation proved to be promising alternatives for localized measurement of these variables. Nevertheless improvement is still needed in order to increase the number of samples measurable per time unit.

The relationship found between density and hydraulic properties does not prove that the target of a selective drought event is one of these traits. Other traits like pit characteristics could be involved. In order to be sure, it may be possible to choose extreme phenotypes and submit them to an artificial selective event, or to decompose the physiological process involved. Bordered pit structure will be a research issue in our future studies.

The next step in our study of the adaptive value of wood and the consequences for tree fitness will be the estimation of broad and narrow-sense heritability and of genetic coefficients of variation. Similar studies of the same species in other environmental conditions and of other species with different types of wood (i.e. broadleaves) are also necessary.

Acknowledgements We would like to thank Jean-Charles Bastien and Leopoldo Sanchez (INRA, Orléans) for their support and for allowing us access to the plant material for this study, and Frédéric Millier for the X-ray microdensitometry and the fieldwork. We would also like to thank the two anonymous referees who improved our manuscript with their comments and suggestions. Research activities were funded by the ANR project 06-VULN-004-01 Dryade. Research stays of the corresponding author at INRA Orléans, France were funded by a grant by the EFPA department of INRA, France and by the Argentina-France bilateral project ECOS-Sud A08B01.

\section{References}

Bond B, Kavanagh K (1999) Stomatal behaviour of four woody species in relation to leaf-specific hydraulic conductance and threshold water potential. Tree Physiol 19:503-510

Bucci SJ, Goldstein G, Meinzer FC, Scholz FG, Franco AC, Bustamante M (2004) Functional convergence in hydraulic architecture and water relations of tropical savanna trees: from leaf to whole plant. Tree Physiol 24:891-899

Cavender-Bares J, Holbrook NM (2001) Hydraulic properties and freezing-induced cavitation in sympatric evergreen and deciduous oaks with contrasting habitats. Plant Cell Environ 24:1243-1256

Cochard H (2002) A technique for measuring xylem hydraulic conductance under high negative pressures. Plant Cell Environ $25: 815-819$ 
Cochard H, Damour G, Bodet C, Tharwat I, Poirier M, Améglio T (2005) Evaluation of a new centrifuge technique for rapid generation of xylem vulnerability curves. Physiol Plant 124:410-418

Cornelius J (1994) Heritabilities and additive genetic coefficients of variation in forest trees. Can J For Res 24:372-379

Cruiziat P, Cochard H, Améglio T (2002) Hydraulic architecture of trees: main concepts and results. Ann For Sci 59:723-752

Dalla-Salda G, Martinez-Meier A, Cochard H, Rozenberg P (2009) Variation of wood density and hydraulic properties of Douglas-fir (Pseudotsuga menziesii (Mirb.) Franco) clones related to a heat and drought wave in France. For Ecol Manag 257:182-189

Decoux V, Varcin E, Leban J (2004) Relationships between the intraring wood density assessed by X-ray densitometry and optical anatomical measurements in conifers. Consequences for the cell wall apparent density determination. Ann For Sci 61:251-262

R Development Core Team (2009) R: a language and environment for statistical computing, R Foundation for Statistical Computing. Vienna, Austria. http://www.R-project.org. Accessed 12 Dec 2009

Domec JC, Gartner BL (2001) Cavitation and water storage capacity in bole xylem segments of mature and young Douglas-fir trees. Trees 15:204-214

Domec JC, Gartner BL (2002a) Age and position-related changes in hydraulic vs. mechanical dysfunction of xylem: inferring the design criteria for Douglas-fir wood structure. Tree Physiol 22:91-104

Domec JC, Gartner BL (2002b) How do water transport and water storage differ in coniferous earlywood and latewood? J Exp Bot 53:2369-2379

Domec JC, Meinzer FC, Lachenbruch B, Housset J (2007) Dynamic variation in sapwood specific conductivity in six woody species. Tree Physiol 27:1389-1400

Dutilleul P, Herman M, Avella-Shaw T (1998) Growth rate effects on correlations among ring width, wood density, and mean tracheid length in Norway spruce (Picea abies). Can J For Res 28:56-68

Guay R, Gagnon R, Morin H (1992) A new automatic and interactive tree ring measurement system based on a line scan camera. For Chron 68:138-141

Hacke UG, Sperry JS, Pockman WT, Davis SD, McCulloh KA (2001a) Trends in wood density and structure are linked to prevention of xylem implosion by negative pressure. Oecologia 126:457-461

Hacke UG, Stiller V, Sperry JS, Pittermann J, McCulloh KA (2001b) Cavitation fatigue: embolism and refilling cycles can weaken cavitation resistance of xylem. Plant Physiol 125:779-786

Johnson GR, Gartner BL (2006) Genetic variation in basic density and modulus of elasticity of coastal Douglas-fir. Tree Genet Genomes 3:25-33

Martinez-Meier A, Sanchez L, Pastorino M, Gallo L, Rozenberg P (2008) What is hot in tree rings? The wood density of surviving Douglas-firs to the 2003 drought and heat wave. For Ecol Manag 256:837-843

Mayr S, Cochard H (2003) A new method for vulnerability analysis of small xylem areas reveals that compression wood of Norway spruce has lower hydraulic safety than opposite wood. Plant Cell Environ 26:1365-1371

McElrone AJ, Pockman WT, Martínez-Vilalta J, Jackson RB (2004) Variation in xylem structure and function in stems and roots of trees to $20 \mathrm{~m}$ depth. New Phytol 163:507-517
Neufeld HS, Grantz DA, Meinzer FC, Goldstein G, Crisosto GM, Crisosto C (1992) Genotypic Variability in Vulnerability of Leaf Xylem to Cavitation in Water-Stressed and Well-Irrigated Sugarcane. Plant Physiol 100:1020-1028

Pittermann J, Sperry J, Hacke U, Wheeler J, Sikkema E (2006) Intertracheid pitting and the hydraulic efficiency of conifer wood: the role of tracheid allometry and cavitation protection. A J Bot 93:1265-1273

Polge H (1966) Etablissement des courbes de variations de la densité $\mathrm{du}$ bois par exploration densitométrique de radiographies d'échantillons prélevés à la tarière sur des arbres vivants. Application dans les domaines technologiques et physiologiques. $\mathrm{PhD}$ thesis, Université de Nancy, Nancy $215 \mathrm{p}$

Rathgeber C, Decoux V, Leban J (2006) Linking intra-tree-ring wood density variations and tracheid anatomical characteristics in Douglas fir (Pseudotsuga menziesii (Mirb.) Franco). Ann For Sci 63:699-706

Rosner S, Klein A, Müller U, Karlsson B (2007) Hydraulic and mechanical properties of young Norway spruce clones related to growth and wood structure. Tree Physiol 27:1165-1178

Rosner S, Klein A, Müller U, Karlsson B (2008) Tradeoffs between hydraulic and mechanical stress responses of mature Norway spruce trunk wood. Tree Physiol 28:1179-1188

Sparks JP, Black RA (1999) Regulation of water loss in populations of Populus trichocarpa: the role of stomatal control in preventing xylem cavitation. Tree Physiol 19:453-459

Sperry JS (1995) Limitations on stem water transport and their consequences. In: Gartner B (ed) Plant stems: physiology and functional morphology. Academic, New York, pp 105-124

Sperry JS, Ikeda T (1997) Xylem cavitation in roots and stems of Douglas-fir and white fir. Tree Physiol 17:275-280

Sperry JS, Tyree MT (1990) Water-stress-induced xylem embolism in three species of conifers. Plant Cell Environ 13:427-436

Sperry JS, Meinzer F, McCulloh K (2008) Safety and efficiency conflicts in hydraulic architecture: scaling from tissues to trees. Plant Cell Environ 31:632-645

Spicer R, Gartner BL (2001) The effects of cambial age and position within the stem on specific conductivity in Douglas-fir (Pseudotsuga menziesii) sapwood. Trees 15:222-229

Stiller V (2009) Soil salinity and drought alter wood density and vulnerability to xylem cavitation of baldcypress (Taxodium distichum (L.) Rich.) seedlings. Environ Exp Bot 67:164-171

Stratton L, Goldstein G, Meinzer F (2000) Stem water storage capacity and efficiency of water transport: their functional significance in a Hawaiian dry forest. Plant Cell Environ 23:99-106

Tyree M, Kolb K, Rood S, Patiño S (1994) Vulnerability to drought induced cavitation of riparian cottonwoods in Alberta: a possible factor in the decline of the ecosystem? Tree Physiol $14: 455-466$

Vander WC, Pammenter NW (1998) Relationship between growth and xylem hydraulic characteristics of clones of Eucalyptus spp. at contrasting sites. Tree Physiol 18:595-600

Zobel B, Sprague J (1998) Juvenile wood in Forest trees. Springer series in wood science. Springer-Verlag, Berlin 